\title{
«El Mapuzungun es naturaleza»: Estrategias didácticas para lenguas originarias desde las ciencias y el arte
}

\section{«Mapuzungun is nature»: Didactic Strategies for Native Languages from Science and Art}

\author{
Al lonko Ernesto Huenchulaf \\ Quien me recordó que los idiomas se escuchan con el corazón.
}

\author{
Andrea Avendaño Caneo \\ Fundadora del Museo de la Nada, Santiago, Chile \\ www.museodelanada.org \\ avendanoandrea@gmail.com
}

\begin{abstract}
Resumen
La escuela primaria puede ser el lugar donde muchos niños descubren el mundo, lamentablemente en ella se sugiere, por parte de los currículos escolares, que existe una manera muy concreta de descubrirlo, callando así, los saberes que los niños ya traen desde sus casas. Muchas escuelas que albergan comunidades indígenas, han contribuido, de manera consciente o no, al matadero cultural de las comunidades. Para este trabajo, intento mostrar cómo desde las artes y las ciencias naturales se apuesta por actividades contra hegemónicas que investigan el entorno y reivindican el espacio de una lengua originaria.

Me centraré en experiencias realizadas en el sur de Chile junto a comunidades mapuche donde se evidencia que el cruce entre arte, ciencia y pueblos originarios permite un mejor desempeño por parte de la comunidad educativa. Finalmente presentaré el allkutün (la escucha), como una «disposición» y saber fundamental en la cultura Mapuche.
\end{abstract}

Palabras clave: arte; educación; mapuzungun; allküntun; la escucha.

\begin{abstract}
Elementary school can be the place where many children discover the world. Unfortunately, inside it school curricula suggest only one way of looking at the world. As a result, children's current knowledge acquired in their home is not covered by teachers. This leads to cultural assimilation of children in schools that are housed in indigenous communities. For this work, I try to show how from the arts and natural sciences there is a commitment to develop counter-hegemonic activities that investigate the environment and claim the space of an original language.

I will focus in activities developed in the South of Chile with Mapuche communities, where the connection of art, science and indigenous people initiates a better settling for schools. Finally, I will introduce allküntun (listening) as a way to understand basic knowledge in Mapuche culture.
\end{abstract}

Keywords: art; education; mapuzungun; allküntu; listening. 


\section{Andrea Avendaño Caneo}

\section{Introducción}

En distintos pueblos originarios de América (norte, sur, centro), el sonido es conceptualizado y representado de maneras diversas. En este sentido la lengua hablada, la oralidad es sonido, y al ser sonido no sólo comunica, sino que llega físicamente a los seres vivientes que «toca». Por ello, en este trabajo, quiero abogar por una mirada más amplia e interdisciplinaria de la importancia de la lengua originaria hablada dentro de las escuelas rurales e indígenas en Sudamérica.

La lengua de algunos pueblos originarios, no sólo permite entenderse, también cura, alienta, y genera vínculos. Si bien la palabra es poesía, canto y mensaje, este elemento va más allá de una cuestión estética y gramatical porque la palabra propicia abundancia, robustece, pero por sobre todo: ordena el mundo.

Por lo tanto, considero vital que dentro de escuelas rurales con niños de origen indígena, se piensen las prácticas cotidianas de una manera extensa. Incorporar el clima, el entorno, los juegos, su caminata diaria, como también su vida familiar es una forma de acercarse a una educación integral real para los niños que provienen de sectores rurales. No hacer esto, sólo contribuye a una forma de neocolonialismo:

Esto se ha insertado como blanqueamiento que ha hecho la escuela como institución en América Latina desde su comienzo. Por lo tanto, la escuela no puede tener una sola manera de evaluar las prácticas culturales de los niños -y menos las de su producción de conocimiento- desde un nivel central que desconoce el contexto en los que se ejerce su educación. (Vega y Avendaño, 2018)

Quiero presentar, cómo en mi trabajo he incorporado herramientas desde la antropología para poder crear material didáctico junto a las escuelas rurales del sur de Chile, donde el conocimiento y su producción requieren otros órdenes, tanto estéticos, como políticos. El material que he creado en escuelas rurales mapuche, ilumina esas otras formas de hacer, y contribuye a que los niños sean partícipes y gestores de su conocimiento. Creo firmemente, en que los niños de escuelas rurales deben tener el espacio para aportar a su propia cultura ${ }^{1}$, puesto que ellos son productores de su cultura (Szulc, 2006, p. 41).

1 En relación a esto he creado un proyecto artístico llamado Museo de la Nada, basado en el derecho y espacio de representación que la escuela debe brindar a niños en contexto rural. Ver: www.museodelanada.org.

\section{$14 \quad$ Lengua \& Sociedad}




\section{Las aves y el allkuntün}

La lengua de los pueblos originarios comunica y denomina territorio. No sólo el mapudungun se basa en la experiencia con la naturaleza, para citar brevemente otro ejemplo, la legua quechua tiene un origen similar: «Las denominaciones quichwa simi, <lengua del valle>, debe entenderse como parte de un sistema inca de designación o de clasificación de los idiomas según el ámbito geográfico en el que eran funcionales» (Itier, 2015, p. 41). Es decir, la geografía del lugar está entremezclada con las denominaciones que hay de los grupos humanos, inclusos de los cultivos, siendo los quichwa simi el idioma del valle o de la tierra templada (Itier, 2015, p. 41). El quechua es lengua y también piso geográfico, y por lo tanto representa el lugar donde las actividades están situadas. Algo parecido sucede con el mapudungun donde, la lengua es naturaleza, tierra, territorio y también sonido, aire, mundo invisible:

Марu, de hecho, puede significar tierra, territorio, espacio, entorno o universo; y dungun, en sus varias acepciones: lengua, lenguaje, voz, sonido y sentido. Mapudungun, al identificar al lenguaje con la tierra, se sale de la lógica antropocéntrica y expresa un territorio de resonancias vastas y múltiples: es la fonética de un universo poblado por seres que susurran, murmuran, hablan, gritan, sollozan o cantan. (Cárcamo-Huachante, 2015, pp. 67)

El quechua como el mapudungun son lenguas alocéntricas donde el marco espacial es requerimiento fundamental para saber dónde nos situamos y en relación a qué sujetos del entorno estamos en contacto.

En el año 2018, gracias a una Beca de la Universidad de Cornell, pude crear actividades donde se triangulaba ciencias naturales, arte y conocimiento ancestral con el objetivo general de revitalizar el mapudungun en la escuela por medio del avistamiento de aves. El Laboratorio de Ornitología de la Universidad de Cornell quería celebrar las aves del lugar, y hacer despertar en los niños el conocimiento que hay en el territorio sobre estos hermanos pájaros. Para ello, tuvimos un evento que reunió a nueve escuelas rurales del sector de Estación Toltén (Región de la Araucanía, Chile). Por otras actividades que ya había realizado, sabía que además de ver e identificar aves, lo que haríamos sería «escucharlas» y advertir su presencia cerca. El evento duró toda una jornada y tuvo la presencia de autoridades mapuche: padres, madres y familias, junto al lonko (jefe) y machis se congregaron. Un kimche (sabio) del lugar fue quien comenzó su conversación 


\section{Andrea Avendaño Caneo}

junto a los niños, padres y profesores. El kimche Florencio Manguilef comenzó el evento contándoles a los niños:

la naturaleza habla y cuando habla emite sonido. La naturaleza y sus seres vivos, nuestros hermanos emiten sonidos. Por más de 15 mil años nosotros los mapuches siempre hemos escuchado cómo nos habla la naturaleza, y ese sonido que Ella emite, lo hicimos palabra, y es ahí donde nace nuestro mapuzungun.

Este nütram, conversación, tiene el principio fundamental de la práctica del allküntun, la escucha. En el mundo mapuche «la escucha» pasa a ser una práctica cultural básica en la comunidad, que va desde escuchar a los abuelos en el fogón a cocina, como también escuchar los mensajes de la naturaleza, mensajes fundamentales para la vida cotidiana. La experiencia de la escucha en el territorio mapuche, sitúa: «allkuntün sería escuchar atentamente, prestar atención» (Cárcamo-Huichante, 2015, p. 64) que es una acción más elaborada, es decir, no es sólo percibir o recibir sonidos, es básicamente la recepción albergante de lo que se dice. Desde mi punto de vista, el allkuntün es una forma intelectual y espiritual de recibir al otro. Es por esto que, al escuchar la naturaleza, no se está definiendo una acción estética, sino más bien, hay una comunicación real, una agencia (Gell, 1998) que muchas veces la educación soslaya.

Esto dista de una mera taxonomía del paisaje. Si bien, para la cultura occidental el paisaje ha sido constantemente una escenografía para las actividades humanas, para las culturas originarias no es así (Lippard, 1990). En el paisaje se entrelaza la vida de seres visibles e invisibles y existe un diálogo constante entre todas las esferas que viven en él.

Quiero mostrar cómo el mapudungun es una lengua que teje la relación entre la gente (che) y los lamgen (hermanos/as) que viven en la naturaleza, el/la mapuche es uno más dentro de la naturaleza y gracias al sonido y a la palabra verbalizada se conecta también con la jerarquía espiritual del territorio, los gnen.

En Estación Toltén, junto a los profesores queríamos honrar este entretejido cultural de sonido, territorio y lenguaje y darle a este conocimiento su lugar dentro de la escuela. Además de poner atención a las consecuencias que trae esta ausencia en el currículo que se enseña a la infancia de pueblos originarios en Chile. 


\section{Las caminatas}

Después del nütram y luego de escuchar a los kimche, hacemos una caminata cerca de la escuela y una parada donde el lonko del sector "pide permiso» a los gnen. Los gnen, son espíritus del lugar, quienes son los dueños de ese paraje, son todas las energías que conviven ahí. Dado este paso, los niños en silencio comienzan a escuchar las aves, y comentar sobre los pájaros que se podían encontrar. Con toda esta información, incorporamos luego el dibujo, para relatar en imágenes toda esta experiencia. Para motivarlos al dibujo, les preguntaba a los niños qué encuentros tuvieron, qué escucharon y cuál puede haber sido el destino de las aves. Las imágenes creadas por los niños, evidencian no sólo la experiencia en el bosque nativo, sino también muestran cómo ellos por medio de las artes visuales gestionan su aprendizaje junto a su comunidad y reconocen su territorio.

Hoy muchas escuelas rurales se entintan de neo-colonialismo, debido a que se impone a los niños a que concebir la producción de conocimiento descontextualizadamente, y esto provoca un desarraigo intelectual en ellos:

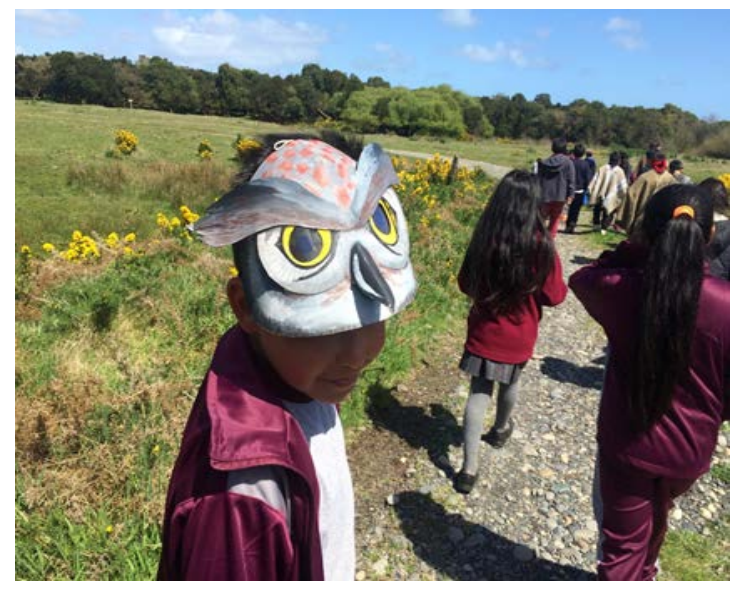

En particular, el conocimiento del sonido se asimila únicamente a la disciplina de la música en la escuela, no permitiendo iluminar la trascendencia que tiene lo acústico en la creación de sentido para niños en una escuela rural. El sonido no sólo se escucha, también sitúa en un lugar, entrega una forma de pertenencia y una relación con el paisaje. Para el caso de niños mapuche, el paisaje sonoro al que ellos están expuestos cada día no corresponde a las maneras en las que se organiza, circula y se percibe el material sonoro que puede haber en la música occidental, sin embargo, sí lo hace en la relación a otras gramáticas y performances en su vida diaria y en otros contextos que implican la vida de la comunidad. 
El arte puede ser la manera de representar códigos culturales que no necesariamente tienen que pasar por la lectoescritura de su lengua. En estas actividades tuve como objetivo, demostrar que el dibujo, puede representar una forma de vida que no tiene voz dentro de la escuela. Es el nütram y el dibujo los medios para hacer dialogar al saber ancestral, la vida en el campo y la ciencia moderna. Sabemos que ese acto equitativo permite una educación intercultural justa.

\section{Conclusiones}

Este trabajo ha intentado dar a conocer actividades donde el arte y las ciencias naturales han formado una alianza junto al conocimiento ancestral para la valoración de la lengua del pueblo mapuche, el mapudungun. Con ello, se quiere destacar cómo las ciencias naturales, una disciplina exacta, junto al arte, una disciplina expresiva, han podido iluminar esas «otras gramáticas» que se deben visualizar para el entendimiento cabal de otra manera de producción de conocimiento. En especial, se quiere subrayar que el allkuntun, la escucha de la palabra, requiere atención, un tiempo distinto y una presencia primordial, incluso espiritual. La escucha es un primer paso para el mundo mapuche, después de escuchar es que se genera la palabra. Ese orden me permite girar en 360 grados en silencio, escuchar mi entorno, y fortalecerme, cuando veo el paisaje que me acompaña me doy cuenta «que estoy acompañado y nada está perdido».

\section{Referencias bibliográficas}

Cárcamo-Huechante, L. (2015). Palabras que sueñan y suenan: la poesía de Leonel Lienlaf como resistencia en tiempos de colonialismo acústico. En Tatiana Calderón y Edith Mora (Eds.), Afpunmapu Fronteras Borderlands. Poética de los confines: Chile-México (pp. 63-84). Valparaíso: Ediciones Universitarias de Valparaíso.

Gell, A.(1998). Art and Agency. Oxford: Oxford University Press.

Itier, C. (2015) Quechua y el sistema inca de denominación de las lenguas. Melanges de la Casa de Velázquez, 45(1), pp. 37-56.

Lippard, L. (1990). Mixed Blessings. Nueva York: The New Press. 
«El Mapuzungun es naturaleza» Estrategias didácticas para lenguas originarias...

Szulc, A. (2006). Antropología y niñez: de la omisión a las «culturas infantiles. En Wilde, G y Schamber, P. (Eds.), Culturas, Comunidades y procesos urbanos contemporáneos (pp. 25-50). Buenos Aires: SB.

Vega, A., y Avendaño, A. (2017). La música como sustancia. Los usos del material sonoro en la construcción de nuevos mundos. En Actas del IV Encuentro hacia una Pedagogía emancipatoria en nuestra América. Buenos Aires. 